\title{
Size Characterization of Urban Airborne Particles Using Sedimentation/Steric Field-Flow Fractionation (Sd/StFFF)
}

\author{
Jae Yong Lee, Seungho Lee, "Young Hong Min, and Dae-Yeung Hyun* \\ Department of Chemistry, Hannam Cniversin, Daejeon 306-791, Korea \\ ${ }^{\dagger}$ Daejeon Institute of Health and Environment. Daejeon 305-338. Korea \\ Received December 2. 2002
}

\begin{abstract}
This study aims to investigate the applicability of Sd/StFFF and to develop a method for size characterization of urban airbome particles. focusing primarily on particles larger than about 1 nun. It was found that the airborne concentration vary with time. although no particular seasonal trend was observed. When averaged over time, the airborne concentration was the lowest in the park areas with $99 \mu \mathrm{g} / \mathrm{m}^{2}$. The apartment. industrial, and central city area showed similar levels of the airbone concentrations with 166.170 . and $171 \mu \mathrm{gg} / \mathrm{m}^{3}$, respectively. The housing area showed the highest airborne concentration with $201 \mu \mathrm{g} / \mathrm{m}^{2}$ anong all tested areas. A power-programmed Sd/StFFF was used for size analysis of airbome particles with the initial field strength of $300 \mathrm{rpm} . t_{\mathrm{a}}=4 . t_{\mathrm{j}}=-16, p=8$. and the flow rate of $7 \mathrm{~mL} / \mathrm{nun}$. It was found that urban airborne samples were mostly populated by particles having diameters between about 5 to $20 \mu \mathrm{m}$. although all have broad size distributions ranging up to about $50 \mu \mathrm{m}$. Under the Sd/StFFF condition used in this study, no significant differences were found in size distributions among the airborne particles collected at different urban sites. and also among those collected at different times.
\end{abstract}

Key Words : Urban airborne particles. Airborne concentration, Particle size distribution. Sedimentation/steric field-flow fractionation $(\mathrm{Sd} / \mathrm{StFFF})$

\section{Introduction}

There exist various sources of airborne particles in urban area. which include waste-incinerators. vehicles. househeating systems. and manufacturing facilities. There are two types of airborne particles. the primary and the secondary particles. The primary particles (usually larger than $1-2 \mu \mathrm{m}$ ) are those emitted directly into air by the sources mentioned above. and the secondary particles (usually smaller than 1-2 $\mu \mathrm{m})$ are those transformed from gases by photo-chemical reactions in the air.

Airborne particles are of environmental concern as they cause visibility reduction, acid rain, and even the climate changes. ${ }^{1.2}$ They may carry toxic chemicals and can cause serious health problems by penetrating and delivering the chemicals into human respiratory systems. ${ }^{3-10}$ It has been reported that the airborne particles. not the chemicals carried by the particles. are responsible for the tumor response due to the particles overloading the lung clearance sy stem. ${ }^{11-13}$

Generally smaller particles are considered to be more dangerous as they can penetrate deeper into the human respiratory system. ${ }^{14}$ Thus to fully assess the environmental impact of airborne particles. it is important to analyze the particle size distribution as well as the toxic elements associated with the particles.

Field-flow fractionation (FFF) is a separation teclunique useful for size characterization of various particlulates. ${ }^{15.16}$ Among FFF sub-techniques. the steric mode of sedimentation

"Corresponding author: Tel: +82-42-629-7473; Fax: +82-42-6297469; e-mail: slee $t$ chem.hannam.ac.kr
FFF ( $\mathrm{Sd} / \mathrm{StFFF}$ ) is particularly useful for the separation/ characterization of particles larger than about $1 \mu \mathrm{m}$. For particles of uniform density. Sd/StFFF provides size-based separation of particles. and allows the $\mathrm{Sd} / \mathrm{StFFF}$ elution profile ("fractogram") to be directly transformed to the size distribution. High resolution and speed have made Sd/StFFF an attractive tool for the analysis of various particulate materials including. biological cells. ${ }^{17}$ chromatographic support particles..$^{18}$ and industrial materials. ${ }^{19}$ It has also been shown that $\mathrm{Sd} / \mathrm{StFFF}$ is potentially useful for size characterization of diesel engine soot particles. ${ }^{2(1) 22}$

This study aims to investigate the applicability of $\mathrm{Sd} /$ StFFF for size characterization of airborne particles. focusing on the primary particles which are usually larger than about $1 \mu \mathrm{m}$.

\section{Theory}

In $\mathrm{Sd} / \mathrm{StFFF}$, the retention time, $t_{r}$ of particles having diameter. $d$. is given by ${ }^{23}$

$$
t_{r}=\frac{w t^{\circ}}{3 \gamma d}
$$

where $w$ is the FFF channel thickness. $t^{\circ}$ the channel void time and $\gamma$ a dimensionless "steric correction factor". If $\gamma$ is assumed to be a constant. $t$. is inversely proportional to $d$. Thus $\mathrm{Sd} / \mathrm{StFFF}$ can provide size-based separations. where larger particles elute earlier than smaller particles. Due to the uncertainty in $\gamma$. the size analysis by $\mathrm{Sd} / \mathrm{StFFF}$ requires a calibration $\left(\log t_{r} w \cdot \log d\right)$. The Sd/StFFF calibration curve is usually linear, and is expressed by ${ }^{24}$ 


$$
\log t_{r}=-S_{d} \log d+\log A
$$

where $A$ is a constant equal to the extrapolated value of the retention time $t$ for the particles of unit diameter. The slope of the calibration curve $\left(\mathrm{d} \log t_{F} / \mathrm{d} \log d\right.$ ) is defined as the size-based selectivity. $S_{d}$. Assuming the band broadening is negligible. an $\mathrm{Sd} / \mathrm{StFFF}$ fractogram can then be transformed into a size distribution by ${ }^{2}=4$

$$
m(d)=c\left(t_{r}\right) \dot{V} S_{i t} A\left(\frac{t_{r}}{A}\right)^{\frac{S_{d i}-1}{S_{i t}}}
$$

where $m(d)$ is the mass-based size distribution. $c(t)$ the fractogram signal (detector response), and $\dot{V}$ the volumetric flow rate $(\mathrm{mL} / \mathrm{min})$ through the channel

\section{Experimental Section}

Calibration standards. The standard particles having narrow size distributions were used for calibration of $\mathrm{Sd} /$ StFFF. Ther were polystyrene-divinyl benzene copolymer latex beads obtained from Duke Scientific Corporation (Palo Alto. CA). The narrow standards having different sized were mixed together without dilution for preparation of a standard-mixture.

Airborne particle collection. For the collection of airborne particles. five areas were chosen in and around an urban area having population of around 1 million. They were (1) park area (denoted as "P"). (2) industrial area (denoted as "I"). (3) Housing area - area crowded by individual houses (denoted as " $\mathrm{H}$ "). (4) city center with heavy traffic (denoted as " $\mathrm{C}$ "). and (5) the area populated by high apartment buildings (denoted as "A"). Three collection sites (A. B. and C) were chosen for the park (P). industrial (I), and the housing area $(\mathrm{H})$. respectively. and one site for each of the other two areas. Total number of collection sites was thus 11. Airborne samples were collected four times from each site (vielding four groups of samples) with an interval of about two months in the span of about 7 months (beginning in December through June in the following year). Each time samples were collected from all 11 sites at the same time. Total number of samples was thus 44 . Table 1 shows four groups of airborne samples (Group-1 4) collected in this study, with each group consisted of 11 samples collected from each site at the same time. For sample collection. an Andersen high volume air sampler (SAUV-1H. Andersen. USA.) was used with a $0.3 \mu \mathrm{m}$ glass microfiber filter (CAT.NO. 1882866.
Whatman international LTD. Maidston. England). For each collection. the collection period was about 24 hours with the average throughput-volume of $1706 \mathrm{~m}^{3}$.

Preparation of airbome dispersion in water. After the sample collection was completed. the glass microfiber filter in the Andersen sampler was cut into small pieces. and placed in a $150 \mathrm{~mL}$ beaker. First. about $10 \mathrm{~mL}$ of ethanol was added to wet the filter paper. Then about $90 \mathrm{~mL}$ of pure water was added. and sonicated in a water-bath (FS60 Ultrasonic Cleaner. Fisher Scientific. Pittsburgh. USA) for 8 hours to remove the air-borne particles from the filter paper. During sonication, the bath-water was changed every hour to prevent over-heating. After removing the filter papers from the beaker. the mixture of the airborne particles and an aqueous medium (water + ethanol) was transferred to a test tube. and centrifuged. The precipitated airborne particles were washed with pure water twice. and then vortexed in an aqueous medium (water containing $0.1 \% \mathrm{FL}-70$ ) for particledispersing.

For acetone-wash of the airborne particles. $1 \mathrm{~mL}$ of the dispersed airborne sample was taken into a test tube and centrifuged. The precipitated airborne particles were washed with pure water. The particles were then vortexed in $5 \mathrm{~mL}$ of acetone for $1 \mathrm{~min}$, and centrifuged for $20 \mathrm{~min}$. After removing acetone. $20 \mathrm{~mL}$ of water was added and vortexed for $1 \mathrm{~min}$ to wash the particles. Acetone-wash was repeated three times. After the acetone-wash, the particles were dispersed in the same medium (water containing $0.1 \%$ FL-70).

Sedimentation Field-Flow Fractionation (SdFFF). The SdFFF system is similar to a Model $\$ 100$ available from Postnova USA (Salt Lake City: Utah). The SdFFF channel is $90 \mathrm{~cm}$ long (tip to tip). $1.5 \mathrm{~cm}$ in breadth. and $0.019 \mathrm{~cm}$ in thickness. The rotor radius is $15.1 \mathrm{~cm}$. The carrier solution was pumped by a M930 HPLC punp (Young-Lin Scientific Co.. Anyang. Korea). The elution of particles was monitored by a UV-106 UV/VIS detector (Linear Instruments. Reno. USA) operating at the fixed wavelength of $254 \mathrm{~nm}$. The detector signal was processed using the software obtained from Postnova USA. Sample injection volume was $20-30 \mu \mathrm{L}$ depending on the sample concentration.

\section{Results and Discussion}

Determination of airborne concentration in air. The airborne concentrations (in $\mu \mathrm{g} / \mathrm{m}^{3}$ ) were determined from the mass differences of the glass microfiber filter placed in the Andersen air sampler before and after the sample

\begin{tabular}{|c|c|c|c|c|c|c|c|c|c|c|c|}
\hline \multirow{2}{*}{ Group No. } & \multicolumn{3}{|c|}{ Park area (P) } & \multicolumn{3}{|c|}{ Industrial area (I) } & \multicolumn{3}{|c|}{ Housing area $(\mathrm{H})$} & \multirow{2}{*}{$\frac{\text { City center }}{C}$} & \multirow{2}{*}{$\frac{\text { Apt. area }}{A}$} \\
\hline & $\mathrm{PA}$ & $\mathrm{PB}$ & $\mathrm{PC}$ & $\mathrm{LA}$ & IB & IC. & $\mathrm{HA}$ & $\mathrm{HB}$ & $\mathrm{HC}$ & & \\
\hline Group-1 & PA-I & PB-I & PC- -1 & $\mathrm{LA}=1$ & IB-I & IC-I & HA-l & $\mathrm{HB}-1$ & $\mathrm{HC}-\mathrm{I}$ & C-1 & A-l \\
\hline Group-2 & $\mathrm{PA}-2$ & PB-2 & $\mathrm{PC}-2$ & $\mathrm{LA}-2$ & IB-2 & IC -2 & $\mathrm{HA}-2$ & $\mathrm{HB}-2$ & $\mathrm{HC}-2$ & $C-2$ & $A-2$ \\
\hline Group-3 & $\mathrm{PA}-3$ & PB-3 & $\mathrm{PC}-3$ & $\mathrm{LA}-3$ & IB-3 & IC -3 & $\mathrm{HA}-3$ & $\mathrm{HB}-3$ & $\mathrm{HC}-3$ & $C-3$ & $A-3$ \\
\hline Group-4 & $\mathrm{PA}-4$ & $\mathrm{~PB}-4$ & $\mathrm{PC}-4$ & $\mathrm{LA}-4$ & IB-4 & $\mathrm{IC}-4$ & HA-4 & $\mathrm{HB}-4$ & $\mathrm{HC}-4$ & $C-4$ & $A-4$ \\
\hline
\end{tabular}

Table 1. Denotations for airbonte samples collected in this study 


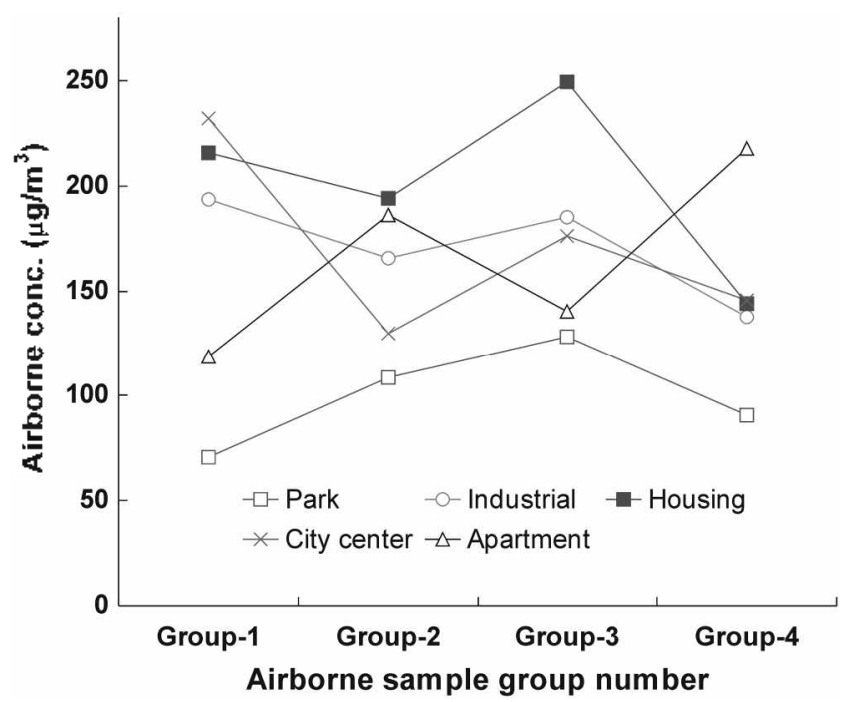

Figure 1. Airbone concentration in various urban areas and in different times.

collections. The results are summarized in Table 2 for all 44 samples. and are also shown in Figure 1. It is noted in Table 2 that for each of the park (P). industrial (I) and housing areas $(\mathrm{H})$, the airbome concentration varies among the three different sites (A. B. and C). That is probably due to the fact that the three sites of each area are in three different areas that are far apart from each other. In Figure 1. the airborne concentrations determined for all three sites (A. B. and C) in each of the park (P). industrial (I) and housing areas $(\mathrm{H})$ were averaged. It can be seen from Table 2 and Figure 1 that the airborne concentrations vary with time in all areas. However no particular seasonal trend was observed. When averaged over time. the airborne concentration was the lowest in the park area with the average airbone concentration of $99 \mu \mathrm{g} / \mathrm{m}^{3}$. The apartment. industrial, and the city center area showed similar levels of the airbone concentrations with 166.170 . and $171 \mu \mathrm{g} / \mathrm{m}^{3}$. respectively: The housing area showed the highest overall airborne concentration of $201 \mu \mathrm{g} / \mathrm{m}^{3}$ among all tested areas. It is interesting to see that the airbone concentration is higher in the housing area. Further study is needed for detailed discussion on the difference in the airborne concentration among different urban areas.

Table 2 also shows the air concentration of Fe determined by ICP. Figure 2 shows the airborne concentration overlaid with the air concentration of $\mathrm{Fe}$ for different samples. where for each sample. both the airbome and the Fe concentrations of the sample in four different groups were averaged. The error bars represent \pm one standard deviation. The airborne concentration is in $\mu \mathrm{g} / \mathrm{m}^{3}$, and the air concentration of $\mathrm{Fe}$ is in $\mathrm{ppb}$. To have both the airbone concentration and the air concentration of $\mathrm{Fe}$ in the same $\mathrm{y}$-scale the air concentration of $\mathrm{Fe}(\mathrm{ppb})$ was multiplied by 100 . Over all the airborne concentration and the air concentration of Fe tend to follow similar trends the sample having high airbome concentration tend to have high concentration of Fe. Similar results were obtained for other groups of the airbone samples (those
Table 2. Airbone concentration in various urban areas

\begin{tabular}{|c|c|c|c|}
\hline \multicolumn{2}{|c|}{ Sample } & \multirow{2}{*}{$\frac{\text { Airbome conc. }\left(\mu \mathrm{g} / \mathrm{m}^{3}\right)}{64.6}$} & \multirow{2}{*}{$\frac{\text { te conc. in air }(\mathrm{ppb})}{0.68}$} \\
\hline Groulp-1 & PA-1 & & \\
\hline & PB-1 & 85.8 & 0.95 \\
\hline & PC-1 & 61.4 & 0.49 \\
\hline & LA-1 & 2300 & 3.46 \\
\hline & IB-l & 171.9 & 2.16 \\
\hline & IC-I & 179.2 & 2.98 \\
\hline & HA-l & 261.1 & 3.04 \\
\hline & $\mathrm{HB}-1$ & 230.5 & 2.61 \\
\hline & $\mathrm{HC}-1$ & 154.7 & 1.60 \\
\hline & $C-1$ & 232.2 & 3.75 \\
\hline & A-l & 118.5 & 0.43 \\
\hline \multirow[t]{11}{*}{ Groulp-2 } & $\mathrm{PA}-2$ & 147.1 & 1.26 \\
\hline & PB-2 & 98.5 & 1.03 \\
\hline & PC-2 & 80.3 & 0.66 \\
\hline & LA-2 & 192.9 & 3.07 \\
\hline & IB-2 & 148.0 & 1.88 \\
\hline & IC -2 & 155.6 & 3.30 \\
\hline & $\mathrm{HA}-2$ & 166.7 & 2.85 \\
\hline & $\mathrm{HB}-2$ & 261.5 & 1.94 \\
\hline & $\mathrm{HC}-2$ & 153.9 & 1.96 \\
\hline & $C-2$ & 129.7 & 4.56 \\
\hline & $A-2$ & 186.1 & 1.10 \\
\hline \multirow[t]{11}{*}{ Group-3 } & $\mathrm{PA}-3$ & 112.4 & 0.18 \\
\hline & $\mathrm{PB}-3$ & 180.4 & 0.30 \\
\hline & $\mathrm{PC}-3$ & 91.3 & 0.52 \\
\hline & $\mathrm{LA}-3$ & 190.6 & 3.28 \\
\hline & IB-3 & 232.1 & 1.73 \\
\hline & IC -3 & 132.7 & 3.27 \\
\hline & $\mathrm{HA}-3$ & 175.9 & 1.05 \\
\hline & $\mathrm{HB}-3$ & 237.1 & 2.40 \\
\hline & $\mathrm{HC}-3$ & 335.1 & 1.19 \\
\hline & $C-3$ & 176.1 & 2.34 \\
\hline & $A-3$ & 140.4 & 0.76 \\
\hline \multirow[t]{11}{*}{ Group-4 } & $\mathrm{PA}-4$ & 72.1 & 0.30 \\
\hline & $\mathrm{PB}-4$ & 139.2 & 0.56 \\
\hline & $\mathrm{PC}_{-4}$ & 60.6 & 0.24 \\
\hline & $\mathrm{LA}-4$ & 165.8 & 2.23 \\
\hline & IB-4 & - & - \\
\hline & IC -4 & 109.2 & 1.52 \\
\hline & $\mathrm{HA}-4$ & 109.3 & 1.16 \\
\hline & $\mathrm{HB}-1$ & 153.0 & 1.76 \\
\hline & $\mathrm{HC}-1$ & 169.3 & 1.26 \\
\hline & $C-4$ & 145.5 & 1.80 \\
\hline & $A-1$ & 217.7 & 0.27 \\
\hline
\end{tabular}

collected at other times). These results suggest that the air concentration of $\mathrm{Fe}$ is closely related with the airbome concentration.

Size detemination of airbome particles using $\mathrm{Sd} /$ StFFF. Based on preliminary studies for the optimization of $\mathrm{Sd} / \mathrm{StFFF}$ for size analysis of airbone particles. a powerprogramuned ${ }^{25} \mathrm{Sd} / \mathrm{StFFF}$ was finally chosen in this study; where the field strength (the channel rotation speed) was 


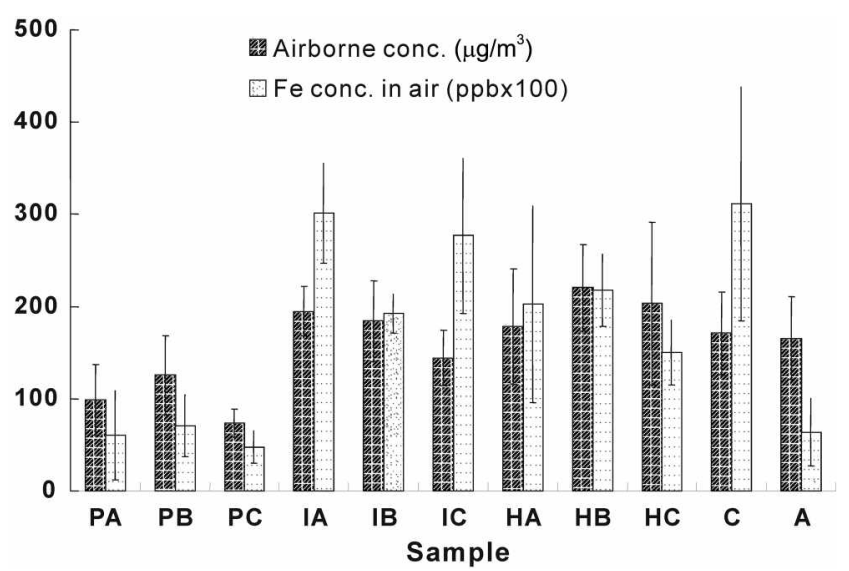

Figure 2. Airbone concentrations and air-concentration of $\mathrm{Fe}$ in airbone samples collected in various urban areas.

gradually decreased during a nun according to a power function. The power-programming is usually employed to prevent excess retention of samples having broad size distributions. and thus to reduce the total analysis time. In this study a power-programming was used for all $\mathrm{Sd} / \mathrm{StFFF}$ analysis of airborne particles with the initial field strength of $300 \mathrm{rpm}$ and other programming parameters set at $t_{\mathrm{a}}=4$. $t_{1}=-16$. and $p=8$. The flow rate was constant at $7 \mathrm{~mL} / \mathrm{min}$. All airbone samples were dispersed in an aqueous medium which was the same as the $\mathrm{Sd} / \mathrm{StFFF}$ carrier liquid. water containing $0.1 \%$ FL- 70 .

Airbone particles may contain some organic compounds. which could cause aggregation of the airbone particles. If present. the aggregated particles need to be disintegrated for reliable and reproducible size data from $\mathrm{Sd} / \mathrm{StFFF}$ analỵsis. Figure 3 shows power-programmed $\mathrm{Sd} / \mathrm{StFFF}$ fractograms of the sample IA-1 (airbome sample collected at the collection

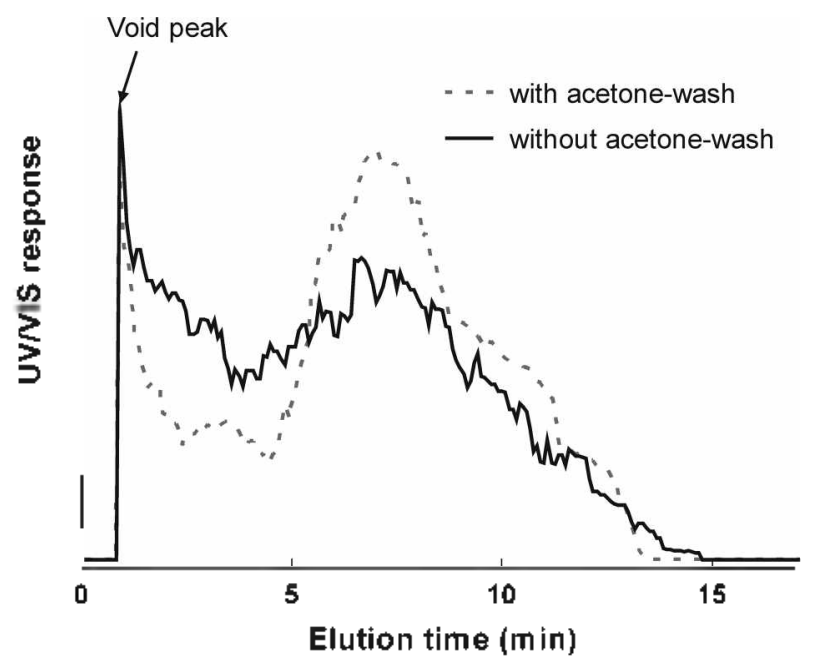

Figure 3. Power-progranmmed SdStFFF fractogranns of LA-l airbone sample with and without acetone-washing. The programming parameters were: initial field strength $=300 \mathrm{pm}, t_{a s}=4, t_{s}=-16$, and $p=8$. The flow rate was $7 \mathrm{~mL} / \mathrm{min}$.

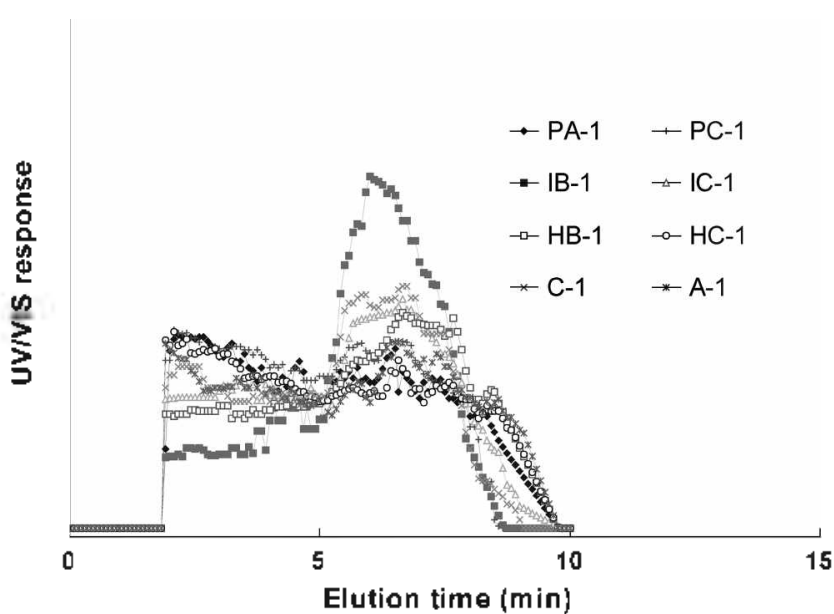

Figure 4. Power-programmed Sd/StFFF fractograms of Group-1 airbome samples. The experimental conditions were the same as those in Figure 3.

site-A of the industrial area in December) obtained with and without acetone-washing (see Experimental Section for the acetone-washing of the airborne particles). As shown in Figure 3, the $\mathrm{Sd} / \mathrm{StFFF}$ elution profile ("fractogram") of acetone-washed airborne particles is clearly different from that of the same sample obtained without acetone-washing. After the acetone-washing. the fractogram signal (detector response) was lowered at the beginning of elution (at lower retention time), while it was increased at higher retention times. As explained earlier in the Introduction section. in $\mathrm{Sd} /$ StFFF, larger particles elute earlier than smaller particles. Figure 3 shows there was an increase in population of smaller particles in the expense of larger particles. suggesting there were some larger aggregated particles in the sample which were disintegrated by the acetone-washing. In this study. all airbone samples were washed with acetone before $\mathrm{Sd} / \mathrm{StFFF}$ analysis.

Figure 4 and 5 show $\mathrm{Sd} / \mathrm{StFFF}$ fractograms and corresponding size distributions of the group-1 samples. respectively. The size distributions shown in Figure 5 were

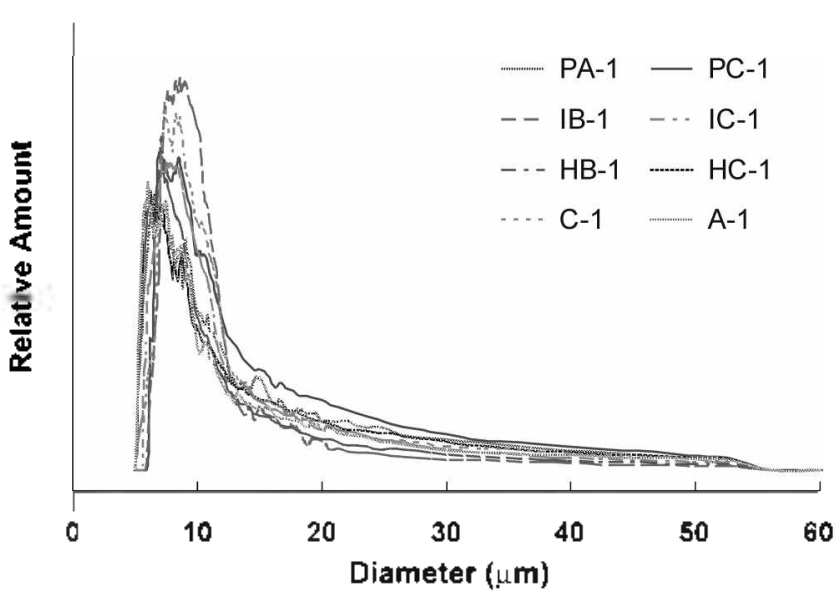

Figure 5. Size distributions of Group-l airbome particles obtained from the fractograms shown in Figure 4. 


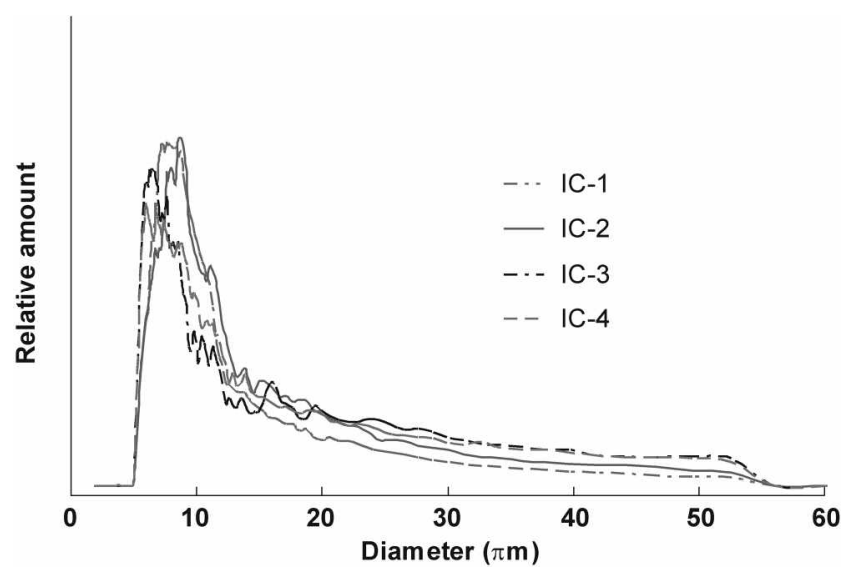

Figure 6. Size distributions of airbome particles collected at an industrial area (IC) at different times.

obtained from the fractograms shown in Figure 4 using Equation 3. Among eleven samples in Group-1. only eight samples are shown in both Figure 4 and 5 (PB-1. IA-1 and HA-1 are missing) to ease the crowdedness of the Figures. In Figure 4, the void peak was removed from each fractogram. For all samples. the $\mathrm{Sd} / \mathrm{StFFF}$ analy sis time was shorter than 10 min. As shown in Figure 4 and 5, all airborne samples were populated mostly by particles having diameters between about 5 to $20 \mu \mathrm{m}$. although all have broad size distributions ranging up to about $50 \mu \mathrm{m}$. No particular trends or significant differences in size distributions were observed among the samples in the same group (samples collected at the same time in different areas). Similar results were obtained for the samples in other groups. The results shown in Figure 5 suggest that there is no significant difference in size distributions of the airbome particles collected in different urban areas.

Figure 6 shows size distributions of the samples IC-1 4 which were samples collected at the site-C of the industrial area at different times. Still. no significant differences were found among the airborne samples collected at the same site at different times. Again similar results were obtained for the samples collected at other sites. The results shown in Figure 6 suggest again that there is no significant seasonal variation in size distributions of the airbome particles collected at the same site.

\section{Conclusions}

In this study: airbone particles were collected at various urban sites and at different times. and were analyzed for airbome concentration and the air concentration of $\mathrm{Fe}$ using ICP. The applicability of $\mathrm{Sd} / \mathrm{StFFF}$ for size analysis of airbome particles was also investigated. Results obtained in this study indicate $S d / S t F F F$ could be a useful tool for size analy'sis of airbome particles. providing not only the average size but also the size distribution. Under the Sd/StFFF conditions used in this study. no significant differences were found in size distributions among the airbome particles collected at different urban areas. and also among those collected at different times. Effort for further optimization of the sample preparation procedure and of the $\mathrm{Sd} / \mathrm{StFFF}$ method is in progress to obtain higher resolution (or the resolving power) in size-based separation of the airborne particles. and thus to improve the accuracy in the size determination. The use of Sd/StFFF method developed in this study could be extended to other types of environmental particles having complex chemical compositions and broad size distributions.

Acknowledgement. This work was supported financially by a research grant from the Hannam University 2003.

\section{References}

1. Finlayson-Pitts. B. J. Pitts, J. N. Amospheric Chemistry: Fundamentals and Experimental Techiques, John Wiley \& Sons: New York. 1986: Chapter 1. 12

2. De Santis. F.: Allegrini. I. Amos. Emiron. 1992. 26.4. 3061.

3. Farthing, W. E. Eniron. Sci. Techmol 1982,16.237A.

4. Cuddihy, R. G.: Griffith, W. C.; Mcclellan. R. O. Eniron. Sci. Technol 1984. 18. 14A.

5. Schwartc. T. Ennir Res. 1993. 62.7.

6. Pope. A.: Dockery: D. W. Am. Rev Dis 1992. 145. 1123.

7. Dockery. D. W.: Pope. C. A.: Xu. X.: Spengler. I. D.: Ware. J. H.: Fav, M. E.; Ferris, B. G.: Speizer, F. E. New Eng. J. Med 1993. 329.1753

8. Seaton, A.: MacNee. W.; Donaldson, K.; Godden. D. Lancet 1995. 345.176.

9. Braun. Ch.: Ackermant1. U.: Schwartz. J.: Gnehtn. H. P.: Rutishauser. M.: Wanner. H. U. Am. Rev Respir 1992. 145.42.

10. Ackennann-Liebrich. U. A.: Lenenverger. Ph.: Schwartz. J.: Schindler, Ch.; Monn. Ch.; SAPALDLA-team. Am. I. Respin: Crit. Care 1 Hed 1997, 155. 122.

11. Donaldson. K.: Beswick. P. H.: Gilmour. P. S. Toxicol Lett. 1996. 88. 293.

12. Donlaldson. K.: Li. X. Y.: MacNee. W. J. Aerosol Sci. 1998. 29. 553.

13. Phalen. R. F. Toxicol. Lett. 1998, 96-97. 263.

14. Kao. A. S.: Friendlander. S. K. Toxicol. 1995, 7, 149

15. Giddings. T. C. Science 1993. 260. 1456.

16. Giddings. T. C. Anal. Chem. 1995. 67. 592A

17. Caldwell. K. D.: Cheng. Z. Q.: Hradechy. P.: Giddings. J. C. Cell Biophss 1984, 6. 233.

18. Giddings, J. C. Moon. M. H. Anal Chem 1991. 63, 2869

19. Moon. M. H.: Giddings, J. C. Anal. Chem. 1992. 64, 3029

20. Kirkland. T. J.: Liebald. W.: Unger. K. K. f. Chomatogr: Sci. 1990. 28.374

21. Kim. W. S.: Park. Y. H.: Shin. T. Y: Lee. D. W. Lee. S. Anal. Chent $1999,71,3265$.

22. Kim. W. S.: Kim, S. H.: Lee, S.: Lim, C. S.; Ryu. J. H. Environ. Sci. Techol. 2001. 35, 1005.

23. Giddings. T. C. Chem Eng Kews 1988. 66. 34

24. Giddings. T. C.: Moon. M. H.: Willianns. P. S.: Myers. M. N. Anal. Chent 1991. 63. 1366.

25. Williams. P. S.; Giddings, J. C. Anal. Chem. 1987. 59. 2038 